Article

\title{
Evaluation of the Water Allocation and Delivery Performance of Jiamakou Irrigation Scheme, Shanxi, China
}

\author{
Yumiao Fan ${ }^{1,2,3}$, Zhanyi Gao ${ }^{1, *}$, Shaoli Wang ${ }^{1,3}$, Haorui Chen ${ }^{1,3}$ (D) and Jing Liu ${ }^{1}$ \\ 1 State Key Laboratory of Simulation and Regulation of Water Cycle in River Basin, China Institute of Water \\ Resources and Hydropower Research, Beijing 100038, China; fanyumiao1990@sina.com (Y.F.); \\ shaoliw@iwhr.com (S.W.); chenhr@iwhr.com (H.C.); jing83694@163.com (J.L.) \\ 2 College of Water Resources and Civil Engineering, China Agricultural University, Beijing 100083, China \\ 3 National Center for Efficient Irrigation Engineering and Technology Research-Beijing, Beijing 10048, China \\ * Correspondence: zhanyi_gao@126.com
}

Received: 17 April 2018; Accepted: 16 May 2018; Published: 18 May 2018

\begin{abstract}
Irrigation performance assessment is an important step in ensuring sustainable agricultural development and improving the capacity of irrigation water management. In this paper, we examined irrigation water management in the Jiamakou Irrigation Scheme in the province of Shanxi (China) using four typical indicators, namely adequacy, efficiency, dependability, and equity. These indicators were calculated both globally and by grouping the data according to different irrigation processes (water allocation and water delivery). Results show that water was poorly allocated, and crop water requirements calculated through the FAO56 Penman-Monteith method was not met timely by scheduled water. They indicate that the overall performance of the scheme was relatively poor, owing to dismal water allocation. Nevertheless, water delivery performance was good, indicating that the scheme was able to deliver adequate and dependable water in an equitable and efficient manner. Our findings suggest that farmers should be trained in allocating irrigation water. The study provides insights into the current behavior of the irrigation scheme and may be used as a base for improvement of irrigation performance.
\end{abstract}

Keywords: water management; assessment; performance indicators; irrigation scheme; water allocation; water delivery

\section{Introduction}

Water resources in China are becoming increasingly scarce because of the growing demands of agriculture, industry, society, and the environment. In particular, water shortage has led to high competition among users and has hindered sustainable development. Irrigation schemes, which are highly productive in agricultural areas, have the largest water demand in the country. Therefore, improving water management in irrigation schemes is vital to national food and water security.

The success of irrigation water management can be measured by how well water delivery meets crops' demand in both time and space [1,2]. Therefore, analyzing the current condition of irrigation schemes and assessing the level of the objective that can be achieved are necessary, and measures can then be taken to reduce the gap between the potential and actual performance of the irrigation scheme. Assessment is considered a useful tool in evaluating and improving the performance of the irrigation scheme [3,4]. Different performance indicators and evaluation perspectives have been proposed or used to evaluate various irrigation schemes in recent decades.

Performance evaluation of the irrigation scheme has been carried out for different purposes, such as performing diagnostic analysis $[5,6]$, understanding irrigation behavior and general irrigation 
trends [7], and comparing the performance of one irrigation scheme with another [8,9]. Evaluation indicators can be categorized into two main groups: external and internal performance. Most irrigation performance assessment studies in China have focused on external performance, especially in crop production, economic output, water use efficiency, and environmental effect [10-12]. However, few studies have measured internal performance, such as adequacy, efficiency, equity, and dependability because of the lack of water measurement or poor quality of records.

Adequacy, efficiency, equity, and dependability are performance objectives considered when evaluating irrigation schemes from the perspective of supply and demand services. Adequacy can be defined as the ability of a system to meet the demand, and it is the fundamental objective of a system. Efficiency expresses the ability of conservation of resources. When a system delivers a greater-than-adequate supply, it cannot be considered efficient. Equity is a measure of the fairness of resource supply and can be defined as spatial uniformity of the ratio of supply and demand. Dependability embodies the ability to supply resource at the right time and expresses the degree of temporal uniformity of the ratio of supply and demand [1].

Irrigation performance evaluation using these four indicators found in literature is mostly conducted by analyzing crop water requirements and actual water supply. For instance, Unal et al. [13] used these four indicators to evaluate the water delivery performance of the Menemen Left Bank Irrigation System in Turkey. They highlighted that factors causing poor irrigation performance derived in part from management, and in part from physical structure. Vandersypen et al. [14] evaluated the irrigation performance of the Office du Niger (Mali) in 1995 and 2004 using these four indicators. They found that the physical rehabilitation of the irrigation network made the irrigation delivery service excellent. Aly et al. [15] calculated the indicators of adequacy, equity, and dependability from the amount of irrigation water supply and demand. Their results indicated that users' association had a positive effect on managing of the tertiary canal. In fact, the evaluation of irrigation performance should not only be based on the analysis of the relationship between crop water requirement and the actual water supply, but also on the relationship between crop water requirement, scheduled water, and actual water supply, that is, the performance of water allocation and water delivery can be assessed separately.

In this study, the Jiamakou Irrigation Scheme (JMIS) was selected as a pilot project for performance assessment. Irrigation performance was assessed and the contributions of water allocation and water delivery to the overall performance were evaluated by using four indicators, namely, adequacy, efficiency, dependability, and equity. Required, scheduled, and delivered amounts of water were used in the calculation of the four indicators. We aim to evaluate the current situation and identify the main causes affecting irrigation performance of JMIS. The contribution of this study is the study of irrigation performance indicator discrimination by water allocation and water delivery. This study enables the determination of the influence of each process on irrigation to consequently improve irrigation performance.

\section{Materials and Methods}

\subsection{Description of JMIS}

JMIS is in Yuncheng City, Shanxi Province, at a latitude of $35^{\circ} 00^{\prime}-35^{\circ} 10^{\prime} \mathrm{N}$, longitude of $110^{\circ} 22^{\prime}-110^{\circ} 51^{\prime} \mathrm{E}$, and elevation from $360-450 \mathrm{~m}$. The irrigation scheme has a semi-arid climate condition, characterized by cold and dry winters, hot and rainy summers, and a mean annual precipitation of $500 \mathrm{~mm}$. The main crops in JMIS are apple and cotton. Irrigation water is usually applied 4-6 times a year under surface irrigation. The irrigation water delivery system in JMIS consists of a pump station, management stations, control structures, a main canal, secondary canals, and tertiary canals, as shown in Figure 1. A total of 11 secondary canals were selected to evaluate the irrigation performance in 2012, 2014, and 2015. The characteristics of the selected secondary canals in 
this study area, such as the location, the irrigated area, the length of canal, and planting crop, are given in Table 1.

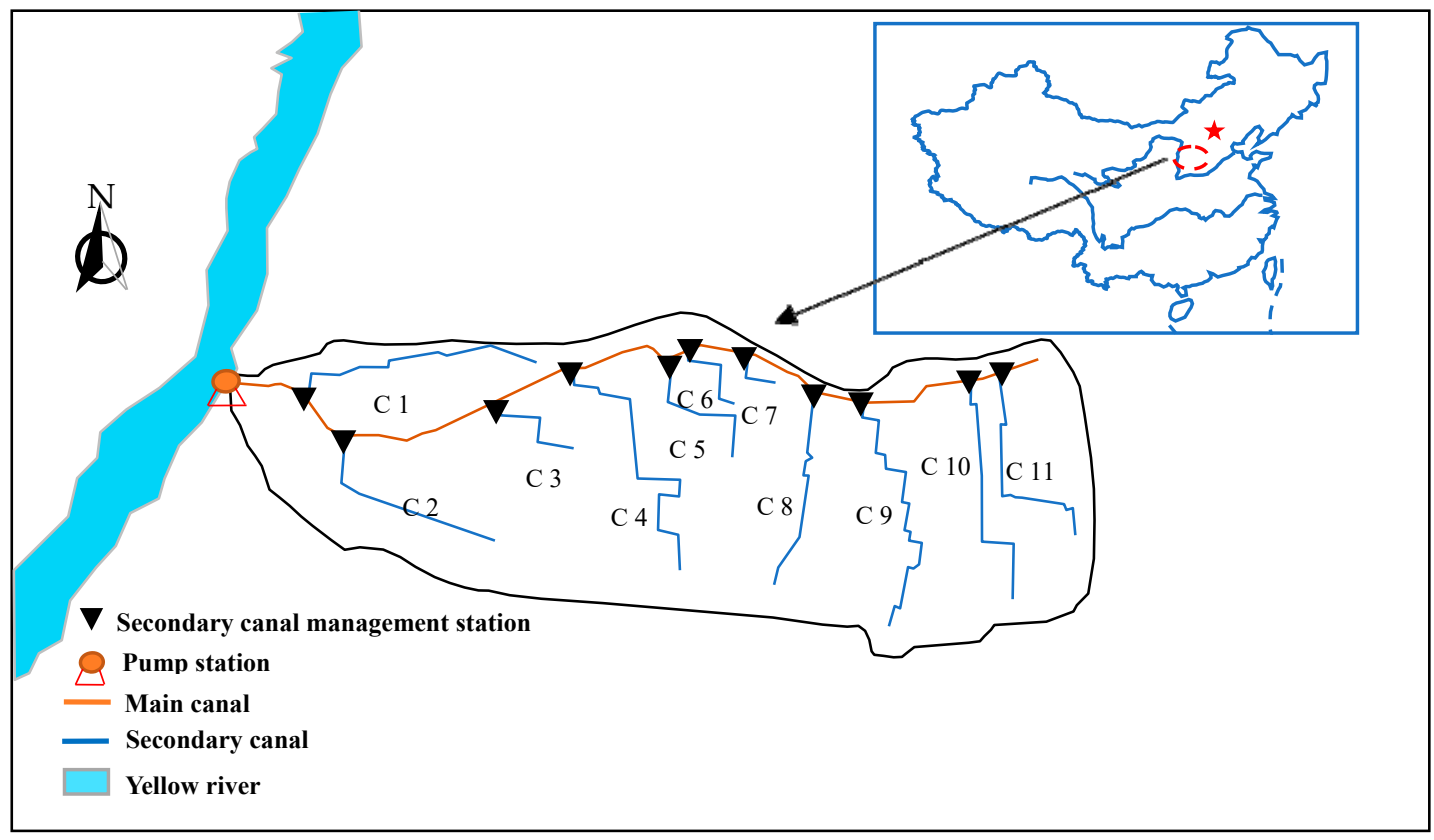

Figure 1. Distribution of main and secondary canals in Jiamakou Irrigation Scheme.

Table 1. Characteristics of selected secondary canals in the study area.

\begin{tabular}{cccccc}
\hline No. & $\begin{array}{c}\text { Secondary } \\
\text { Canal Name }\end{array}$ & $\begin{array}{c}\text { Distance from } \\
\text { Pump Station }(\mathbf{m})\end{array}$ & $\begin{array}{c}\text { Irrigated } \\
\text { Area (ha) }\end{array}$ & $\begin{array}{c}\text { Total Length } \\
\text { of Canal (m) }\end{array}$ & $\begin{array}{c}\text { Cropping Pattern } \\
\text { (Apple: Cotton) }\end{array}$ \\
\hline C 1 & Puli & 2664 & 1139 & 11,117 & $0.32: 0.68$ \\
C 2 & Secondary canal 1 & 5267 & 2235 & 26,274 & $0.55: 0.45$ \\
C 3 & Secondary canal 3 & 13,093 & 595 & 4693 & $0.85: 0.15$ \\
C 4 & Secondary canal 4 & 16,655 & 1729 & 21,600 & $0.55: 0.45$ \\
C 5 & Secondary canal 5 & 20,569 & 989 & 10,800 & $0.67: 0.33$ \\
C 6 & Secondary canal 6 & 21,274 & 209 & 2788 & $0.74: 0.26$ \\
C 7 & Secondary canal 7 & 24,252 & 229 & 3928 & $0.79: 0.21$ \\
C 8 & Secondary canal 8 & 29,300 & 665 & 9200 & $0.24: 0.76$ \\
C 9 & Secondary canal 9 & 30,100 & 754 & 1400 & $0.74: 0.26$ \\
C 10 & Secondary canal 10 & 35,062 & 980 & 19,488 & $0.57: 0.43$ \\
C 11 & Secondary canal 11 & 36,321 & 995 & 28,500 & $0.68: 0.32$ \\
Total & - & - & 10,517 & - & - \\
\hline
\end{tabular}

The timely availability of water for crops has greatly contributed to local agricultural and economic development in JMIS, and the irrigation scheme has formed a systematic irrigation water management mode. The irrigation water management in JMIS includes two procedures, namely water allocation and water delivery. Water allocation refers to the process where farmers allocate irrigation water to crops according to traditional irrigation experience and submit their orders to the managers of the irrigation scheme. Water delivery refers to the process where the managers of the irrigation scheme operate the irrigation water delivery system to supply water to crops according to farmers' water orders, and it is mainly affected by the physical system and operational decision of canals.

JMIS is managed by the Irrigation Scheme Administration Bureau (ISAB), and the following departments conduct the management of irrigation water: Pump Management Station, Main Canal Management Center, Secondary Canal Management Station, and Tertiary Canal Operating Organization. 
Figure 2 shows the relationship between these departments. During the irrigation period, farmers submit daily orders directly to the Tertiary Canal Operating Organization. The Secondary Canal Management Station then receives these orders and passes the information on to the Main Canal Management Center. According to this information and water-use efficiency in the canal system, the Main Canal Management Center issues instructions of pump operation (run number, setting time) to the Pump Management Station. The four departments simultaneously control their own hydraulic structures to supply water to the lower canals; and they check, monitor, and record the water delivered. Flow measurement is at the core of irrigation water management. Each canal in JMIS is equipped with accurate flow measuring facilities: Parshall flume for the secondary canal and non-throat flume for the tertiary canal.

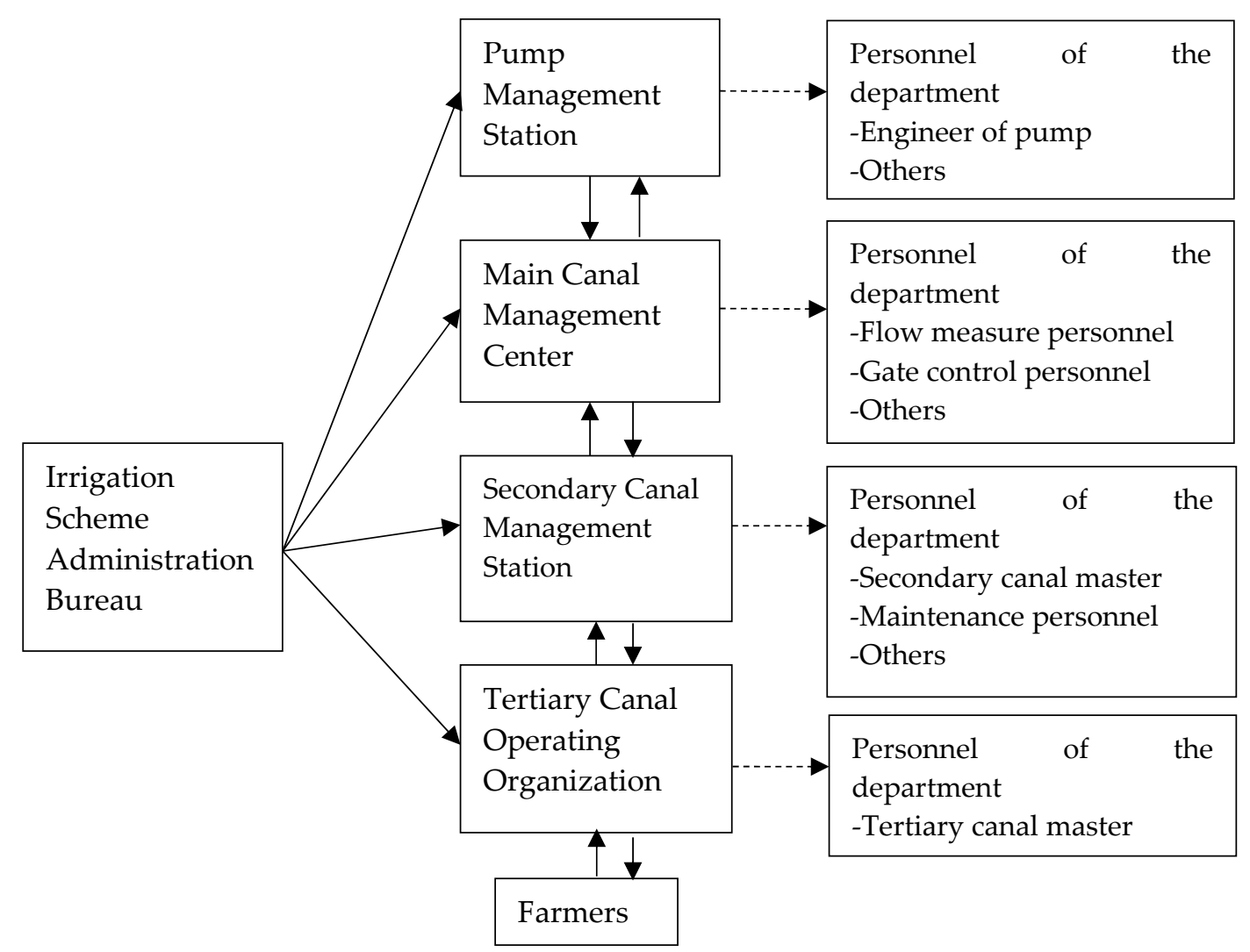

Figure 2. Organization chart in the process of irrigation water delivery management.

\subsection{Crop Evapotranspiration and Irrigation Water Requirement}

Crop evapotranspiration is calculated by correcting the reference evapotranspiration with the crop coefficient as shown in Equation (1):

$$
E T_{\mathcal{c}}(t)=k_{\mathrm{c}}(t) E T_{0}(t)
$$

where $E T_{c}$ is crop evapotranspiration, $t$ is time, and $k_{c}$ is crop coefficient, the value of which can be obtained from the results of two experimental areas near the study area (see Figure 3) [16,17]. The distance between the two experimental areas and the study area is approximately $200 \mathrm{~km}$. Similar climatic conditions, soil, and farmland management make it possible to use the $k_{c}$ values of the two experimental areas in this study area. Meanwhile, $E T_{0}$ is reference evapotranspiration and can be calculated by the FAO56 Penman-Monteith method according to climate data observed at meteorological stations near JMIS [18]. 


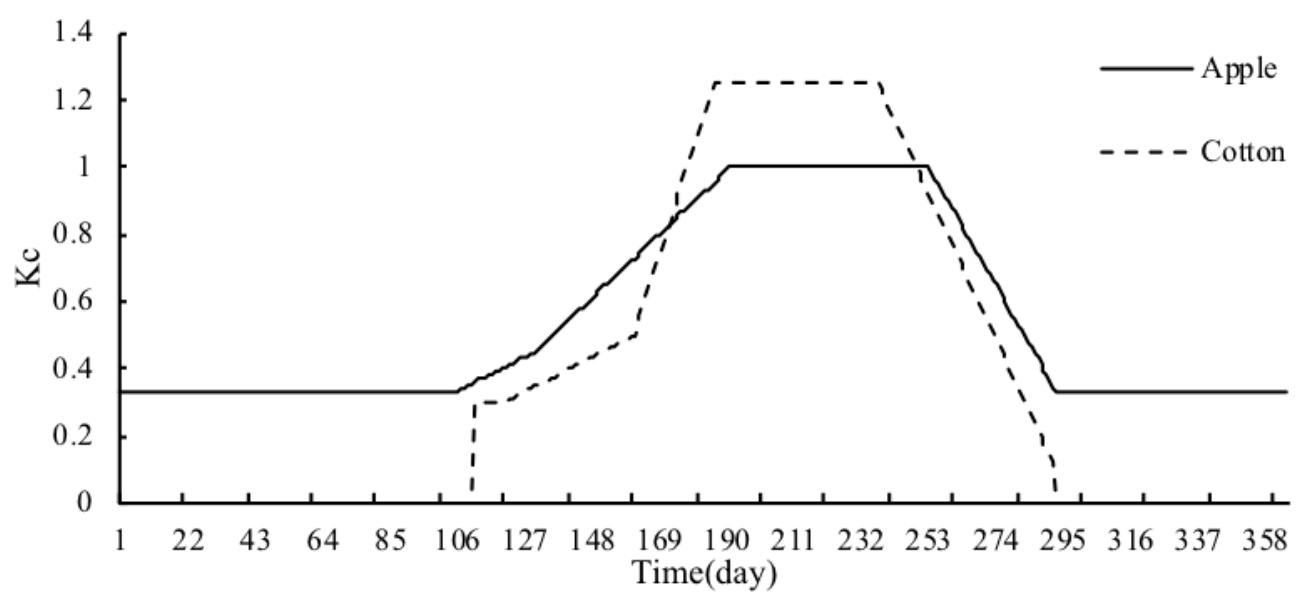

Figure 3. Crop coefficients of apple and cotton in JMIS.

Net irrigation water requirement of crop and irrigation water requirement for the secondary canals are formulated as Equations (2) and (3):

$$
\begin{gathered}
Q_{\text {Rnet }}(t)=\left(E T_{c a}(t)-E P(t)\right) A_{a}+\left(E T_{c c}(t)-E P(t)\right) A_{c} \\
Q_{R}(t)=Q_{\text {Rnet }}(t) /\left(W U E_{f} \times W U E_{c}\right)
\end{gathered}
$$

where $Q_{R n e t}$ is net irrigation water requirement, $E T_{\mathcal{C} a}$ is $E T_{\mathcal{c}}$ of apple, $E T_{\mathcal{~ c}}$ is $E T_{\mathcal{c}}$ of cotton, and $E P$ is defined as the effective precipitation in crop-growing season and is equal to the total precipitation minus the loss from surface runoff. If $E P$ is greater than $E T_{\mathcal{C}}, Q_{R n e t}$ is considered equal to zero. The variables $A_{a}$ and $A_{c}$ represent the planting areas of apple and cotton within the secondary canal control area, respectively. $Q_{R}$ is irrigation water requirement, $W U E_{f}$ and $W U E_{c}$ represent water use efficiency in the field and canal system, respectively. According to the experiments in this irrigation scheme, water efficiency in the field and canal systems is, respectively, assumed to be 0.95 and 0.85 .

The variable $E P$ is mainly related to precipitation amount at a rainfall event, topography, soil infiltration rate, and field management. It is regarded as an invalid precipitation when the rainfall is extremely small. In contrast, surface runoff will occur if precipitation is excessive. In this study, EP is formulated as Equation (4):

$$
E P=\alpha P
$$

where $P$ is the total amount of precipitation at a time, and $\alpha$ is the coefficient of effective precipitation. Generally, $\alpha=0$ when $P<5 \mathrm{~mm}, \alpha=1.0$ when $5 \mathrm{~mm} \leq P \leq 50 \mathrm{~mm}$, and $\alpha=0.8$ when $50 \mathrm{~mm}>P$ [19].

\subsection{Scheduled Water and Delivered Water}

We define the amount of scheduled water as the amount of water allocated to the secondary canal at a time, which is determined by the water requested by the farmers and the water use efficiency in the canal system. Scheduled water is formulated as Equation (5):

$$
Q_{s}(t)=Q_{r}(t) / W U E_{c}
$$

where $Q_{S}$ is the scheduled water, and $Q_{r}$ is water requested by farmers. As previously mentioned, the farmers' water orders are submitted to ISAB daily, so the data of requested water in 2012, 2014, and 2015 was collected directly from ISAB.

The actual amount of delivered water to the secondary canal at a time, denoted herein as $Q_{D}$, was measured by the Parshall flume managed by the Secondary Canal Management Station. Water levels were measured and recorded at $1 \mathrm{~h}$ intervals during the irrigation season and converted into 
discharges using the flow formula of Parshall flume. Similar to $Q_{r}, Q_{D}$ was collected directly from ISAB of JMIS (Table 2).

Table 2. $E P, Q_{R}, Q_{S}$, and $Q_{D}$ values during 2012, 2014, and 2015.

\begin{tabular}{|c|c|c|c|c|c|}
\hline Year & Month & $E P(\mathrm{~mm})$ & $Q_{R}\left(10^{4} \mathrm{~m}^{3}\right)$ & $Q_{S}\left(10^{4} \mathrm{~m}^{3}\right)$ & $Q_{D}\left(10^{4} \mathrm{~m}^{3}\right)$ \\
\hline \multirow{13}{*}{2012} & Total & 329 & 3923 & 4314 & 4265 \\
\hline & January & 0 & 53 & 0 & 0 \\
\hline & February & 0 & 101 & 91 & 85 \\
\hline & March & 14 & 51 & 627 & 598 \\
\hline & April & 9 & 256 & 648 & 651 \\
\hline & May & 32 & 315 & 850 & 889 \\
\hline & June & 12 & 1679 & 1173 & 1180 \\
\hline & July & 131 & 134 & 181 & 157 \\
\hline & August & 43 & 1197 & 534 & 497 \\
\hline & September & 66 & 0 & 0 & 0 \\
\hline & October & 16 & 0 & 0 & 0 \\
\hline & November & 7 & 45 & 202 & 199 \\
\hline & December & 0 & 93 & 9 & 9 \\
\hline \multirow{13}{*}{2014} & Total & 557 & 2110 & 3578 & 3636 \\
\hline & January & 0 & 123 & 0 & 0 \\
\hline & February & 6 & 18 & 0 & 0 \\
\hline & March & 0 & 221 & 791 & 785 \\
\hline & April & 73 & 0 & 109 & 115 \\
\hline & May & 57 & 0 & 160 & 167 \\
\hline & June & 90 & 136 & 965 & 1009 \\
\hline & July & 57 & 1285 & 945 & 898 \\
\hline & August & 85 & 327 & 176 & 229 \\
\hline & September & 174 & 0 & 0 & 0 \\
\hline & October & 4 & 0 & 0 & 0 \\
\hline & November & 11 & 0 & 401 & 392 \\
\hline & December & 0 & 0 & 31 & 42 \\
\hline \multirow{13}{*}{2015} & Total & 481 & 2832 & 3421 & 3310 \\
\hline & January & 0 & 92 & 0 & 0 \\
\hline & February & 0 & 151 & 0 & 0 \\
\hline & March & 24 & 0 & 756 & 757 \\
\hline & April & 52 & 0 & 19 & 17 \\
\hline & May & 52 & 0 & 645 & 647 \\
\hline & June & 87 & 88 & 677 & 731 \\
\hline & July & 47 & 1112 & 744 & 511 \\
\hline & August & 26 & 1389 & 535 & 582 \\
\hline & September & 84 & 0 & 45 & 65 \\
\hline & October & 65 & 0 & 0 & 0 \\
\hline & November & 43 & 0 & 0 & 0 \\
\hline & December & 0 & 0 & 0 & 0 \\
\hline
\end{tabular}

\subsection{Determination of Performance Indicators}

The overall performance of the irrigation scheme was calculated by the indicators of adequacy, efficiency, equity, and dependability (Equation (6a-d)) and was considered satisfactory only when the performance levels of water allocation and water delivery were high. The performance of water allocation and water delivery were also determined according to the four indicators and were used in the analysis of the farmers' capacity to allocate water and the manager's capacity to deliver the same. The performance indicators of water allocation were calculated by the scheduled water and 
the required water. Meanwhile, the performance indicators of water delivery was calculated by the amount of delivered water and scheduled water.

$$
\begin{gathered}
P_{A}=\frac{1}{T} \sum_{T}\left(\frac{1}{R} \sum_{R} P_{A \text { single }}\right),\left\{\begin{array}{c}
P_{\text {Asingle }}=Q_{D} / Q_{R} \text { if } Q_{D} \leq Q_{R} \\
P_{\text {Asingle }}=1 \quad \text { if } Q_{D}>Q_{R}
\end{array}\right. \\
P_{F}=\frac{1}{T} \sum_{T}\left(\frac{1}{R} \sum_{R} P_{F \sin g l e}\right),\left\{\begin{array}{c}
P_{F \sin g l e}=Q_{R} / Q_{D} \text { if } Q_{R} \leq Q_{D} \\
P_{F \sin g l e}=1 \quad \text { if } Q_{R}>Q_{D}
\end{array}\right. \\
P_{D}=\frac{1}{R} \sum_{R} C V_{T}\left(Q_{D} / Q_{R}\right) \\
P_{E}=\frac{1}{T} \sum_{T} C V_{R}\left(Q_{D} / Q_{R}\right)
\end{gathered}
$$

$P_{A \text { single }}$ represents the indicator of adequacy in a secondary canal and a month, and $P_{A}$ represents the indicator of adequacy in the irrigation scheme and can be calculated by the spatial and temporal average of $P_{A \sin g l e}$. When $P_{A}$ is close to or equal to one, the delivered water was sufficient for crop water requirement. $T$ is the time (12 months in total) in which performance was evaluated. $R$ represents the secondary canals ( 11 canals in total), the performance of which was to be determined. $P_{F \text { single }}$ represents the indicator of efficiency in a secondary canal and a month, and $P_{F}$ represents the indicator of efficiency in the irrigation scheme and can be calculated by the spatial and temporal average of $P_{F \sin \text { gle }} . P_{F}=1$ reveals that irrigation water was efficient and no water was wasted. Meanwhile, $P_{D}$ and $P_{E}$ represent indicators of dependability and equity, respectively, which show the fairness and reliability of water supply in the irrigation scheme by comparing the adequacy of different secondary canals and months. When $P_{D}$ and $P_{E}$ values were close to or equal to zero, this indicates that water delivery was uniform from canal to canal and month to month. $C V_{T}\left(Q_{D} / Q_{R}\right)$ is temporal coefficient of variation of $Q_{D} / Q_{R}$ over the period T. Similarly, $C V_{R}\left(Q_{D} / Q_{R}\right)$ is the spatial coefficient of variation of $Q_{D} / Q_{R}$ over the region $R$. When we calculate $Q_{D} / Q_{R}$ or $Q_{R} / Q_{D}$ in this paper, we assume that the ratio is 1 if the denominator is zero.

In general, $P_{A}, P_{F}, P_{D}$, and $P_{E}$ represent the relationship between the actual water supply and crop water requirement as the comprehensive reflection of performance in the irrigation scheme. The evaluation standard for performance indicators was formed by Molden and Gate as shown in Table 3 [1]. According to the evaluation standard, the performance can be classified as good, fair, or poor.

Table 3. Evaluation standard for performance indicators.

\begin{tabular}{cccc}
\hline \multirow{2}{*}{ Measure } & \multicolumn{3}{c}{ Performance Classes } \\
\cline { 2 - 4 } & Good & Fair & Poor \\
\hline$P_{A}$ & $0.90 \leq P_{A} \leq 1.00$ & $0.80 \leq P_{A}<0.9$ & $P_{A}<0.8$ \\
$P_{F}$ & $0.85 \leq P_{F} \leq 1.00$ & $0.70 \leq P_{F}<0.85$ & $P_{F}<0.70$ \\
$P_{D}$ & $0 \leq P_{D} \leq 0.10$ & $0.10<P_{D} \leq 0.25$ & $P_{D}>0.25$ \\
$P_{E}$ & $0 \leq P_{E} \leq 0.10$ & $0.10<P_{E} \leq 0.20$ & $P_{E}>0.2$ \\
\hline
\end{tabular}

The calculation of Equation $(6 a-d)$ shown that the result of the performance indicators were affected by the calculation unit (time and space). Due to the persistence of crop water requirements and the intermittent trait of irrigation, it was easy to find that if the calculation unit is small, the performance of irrigation will be poor, and vice versa. However, if the calculation unit is too small or too large, it will have no practical significance on the performance evaluation of the irrigation scheme. In related papers [13-15,20], most of the studies used the month as the unit of time, and the canal 
control area as the unit of space. Therefore, in this paper, the month and the secondary canal control area were chosen as the time unit and the space unit, respectively.

When the performance of water allocation is analyzed, $P_{A A}, P_{A F}, P_{A D}$, and $P_{A E}$ are selected to represent the performance of water allocation with respect to adequacy, efficiency, dependability, and equity in the irrigation scheme. The calculation method of $P_{A A}, P_{A F}, P_{A D}$, and $P_{A E}$ is similar to that of $P_{A}, P_{F}, P_{D}$, and $P_{E}$ (Equation (6a-d)). The difference between the two methods is that the former is based on the ratio $Q_{S} / Q_{R}$, whereas the latter is based on the ratio $Q_{D} / Q_{R} . P_{A A}, P_{A F}, P_{A D}$, and $P_{A E}$ represent the relationship between the scheduled water and crop water requirement. The amount of scheduled water in JMIS is determined directly by the farmers' order without the intervention of the managers of the irrigation scheme. Therefore, the performance of water allocation is mainly characterized by the cultivation level of farmers in this irrigation scheme.

Similarly, when the performance of water delivery is analyzed, $P_{D A}, P_{D F}, P_{D D}$, and $P_{D E}$ are selected to represent the performance of water delivery with respect to adequacy, efficiency, dependability, and equity, reflecting the capability of the irrigation scheme to deliver water. $P_{D A}, P_{D F}$, $P_{D D}$, and $P_{D E}$ can also be calculated using the method in Equation (6a)-(6d). The difference is that $P_{D A}, P_{D F}, P_{D D}$, and $P_{D E}$ are calculated based on the ratio $Q_{D} / Q_{S}$. These indicators can effectively express whether the scheduled water can be delivered to the field by the physical system and canal operation decision. Thus, $P_{D A}, P_{D F}, P_{D D}$, and $P_{D E}$ snify a series of indicators for the capacity of the irrigation scheme to provide services to the farmers.

\section{Results and Discussion}

\subsection{Performance of Water Allocation and Water Delivery}

The performances of water allocation and water delivery of this irrigation scheme are summarized in Table 4. These indicators indicate a poor performance with respect to the objectives of adequacy, efficiency, dependability, and equity in the water allocation process. The calculated crop water requirement based on the FAO56 Penman-Monteith method cannot be met by the scheduled water in a timely manner. Although this situation is believed to occur because of the continuous water demand for crop and intermittent irrigation, it also partly reflects on the incompetence of farmers in establishing an irrigation schedule.

The values of $P_{A D}$ show that the allocation performance with respect to dependability was extremely poor, indicating that the relative water allocation was uneven over time. Through the values of $Q_{R}$ and $Q_{S}$ in Table 2, we can intuitively sense a mismatch between scheduled water and required water over time. From the total amount of the year, the scheduled water was greater than the required water, especially in 2014 (wet year). The amount of scheduled water was 1.7 times that of required water in 2014, but the crop water requirement was met only in some months under the influence of the unscientific water allocation. These results may indicate that the farmers' water orders were mainly influenced by traditional and fixed irrigation ideas, and the scientific method of water allocation that allocates water according to the crop water requirement was not reasonably considered.

As shown in Table $4, P_{D A}$ values were above $0.9, P_{D F}$ values were above $0.85, P_{D D}$ values were between 0.1 and 0.25 , and $P_{D E}$ values were between 0.1 and 0.2 in the selected years. According to the evaluation criteria, the performances of delivery contribution were good with respect to adequacy and efficiency and were fair with respect to dependability and equity. The operation and management of the irrigation water delivery system in this irrigation scheme was good, and the system could deliver adequate and dependable water to meet the scheduled water in an equitable and efficient manner in most cases. The results also indicate that this irrigation scheme can provide good service to farmers. Some studies have shown that a flexible water delivery system and good water delivery service capacity are important ways to improve water use efficiency and promote modernization of irrigation schemes [21-23]. In recent years, the Chinese government has made efforts to promote the 
modernization of irrigation schemes. The good water delivery management and service capabilities of JMIS can serve as a reference for the modernization of other irrigation schemes in the country.

Table 4. Summary of performance for the irrigation scheme.

\begin{tabular}{ccccccc}
\hline \multirow{5}{*}{ Adequacy } & Indicator & $\mathbf{2 0 1 2}$ & $\mathbf{2 0 1 4}$ & $\mathbf{2 0 1 5}$ & Average \\
\hline \multirow{3}{*}{ Efficiency } & Overall performance & $P_{A}$ & 0.61 & 0.73 & 0.65 & 0.66 \\
& Water allocation & $P_{A A}$ & 0.62 & 0.71 & 0.66 & 0.66 \\
& Water delivery & $P_{D A}$ & 0.93 & 0.98 & 0.93 & 0.95 \\
\hline \multirow{5}{*}{ Dependability } & Overall performance & $P_{F}$ & 0.77 & 0.47 & 0.49 & 0.58 \\
& Water allocation & $P_{A F}$ & 0.71 & 0.48 & 0.48 & 0.56 \\
& Water delivery & $P_{D F}$ & 0.97 & 0.88 & 0.90 & 0.92 \\
\hline \multirow{3}{*}{ Equity } & Overall performance & $P_{D}$ & 1.48 & 1.26 & 1.64 & 1.46 \\
& Water allocation & $P_{A D}$ & 1.52 & 1.25 & 1.56 & 1.44 \\
& Water delivery & $P_{D D}$ & 0.21 & 0.21 & 0.25 & 0.23 \\
\hline & Overall performance & $P_{E}$ & 0.69 & 0.17 & 0.12 & 0.32 \\
& Water allocation & $P_{A E}$ & 0.69 & 0.18 & 0.12 & 0.33 \\
\hline
\end{tabular}

\subsection{Overall Performance of the Irrigation Scheme}

The values of $P_{A}, P_{F}, P_{D}$, and $P_{E}$ in 2012, 2014, and 2015 are listed in Table 4 . According to the evaluation standard in Table 3 , the values of $P_{A}$ were less than 0.8 , indicating that the delivered water was insufficient to satisfy the crop water requirement in the selected years. The efficiency indicator was fair in 2012 and poor in 2014 and 2015. These results show that the delivered water was greater than the crop water requirement in some cases. The values of $P_{D}$ were much greater than 0.25 in 2012 , 2014, and 2015, and thus irrigation water was not supplied to the secondary canals at the right time. The secondary canal received more water than required in some months and received less water in some months. The equity indicator was poor in 2012 and fair in 2014 and 2015, showing that the delivered water was uneven in various secondary canals in 2012, and some secondary canals received too much water, whereas some did not receive enough.

Table 5 lists a comparison of the evaluation results that were reported in other studies. Compared to other studies, the results of this study showed that the overall performance of JMIS was generally poor, especially with respect to dependability. The two processes of irrigation water allocation and water delivery determined the overall performance in JMIS. The above analysis shows that compared to water delivery, water allocation had a greater contribution to the poor performance of this irrigation scheme. Although the scheduled water could be supplied by delivered water with good water delivery performance, the overall performance of this irrigation scheme was relatively poor because of the poor performance of water allocation. These results suggest that additional efforts are needed to improve the performance of water allocation and the overall performance of this irrigation scheme. These efforts include the use of modern field-monitoring equipment and technology and the use of a guide for the establishment of farmers' water orders under different climatic conditions. In addition, communication between irrigation scheme managers and farmers must be strengthened, especially in periods of peak water demand.

Table 5. Comparison of the evaluation results reported in other studies.

\begin{tabular}{ccccccc}
\hline Categories & Country & Year & Crop & Adequacy & Efficiency & Dependability Equity \\
\hline Unal et al. [13] & Turkey & 1999 & Cotton and vegetable & 0.93 & 0.83 & 0.81 \\
Vandersypen et al. [14] & Mali & 2004 & paddy rice & 0.91 & 0.59 & 0.71 \\
Aly et al. [15] & Egypt & 2003 & Paddy rice, cotton and maize & 0.66 & - & 0.67 \\
Nam et al. [20] & South Korea & 2013 & paddy rice & 0.87 & 0.86 & 0.26 \\
\hline
\end{tabular}




\section{Conclusions}

The current irrigation behavior and irrigation performance in JMIS was analyzed and evaluated quantitatively by using adequacy, efficiency, dependability, and equity. The overall performance of this irrigation scheme was classified as poor. Indicators of the overall performance show that the water supply of this irrigation scheme was inadequate and inefficient, and the required water was not supplied at the right time in an equitable manner. Further, analysis found that the performance of this irrigation scheme was poor in terms of water allocation, but good in terms of water delivery, indicating that this scheme had an unscientific water allocation method. Therefore, the allocation method could be the main cause affecting the irrigation performance of JMIS and matching the amount scheduled water delivered to the crop water requirement requires additional effort.

By calculating performance indicators according to water allocation and water delivery, it is possible to determine the influence of each individual process on irrigation management and take subsequent measures to improve irrigation performance.

Author Contributions: Y.F., Z.G. and S.W. designed this study; Y.F., H.C. performed the analysis and led the writing of this paper; J.L. helped analyzed the data for the research; and Y.F., H.C. and J.L. worked on improving and finalizing the manuscript.

Funding: This research was funded by [The National Key Research and Development Program of China] grant number [2017YFC0403205, 2017YFC0403302, 2017YFC0403503, 2016YFC0501301]; [Basic Research Fund of China Institute of Water Resources and Hydropower Research] grant number [GG0145B502017]; [National Natural Science Foundation of China] grant number [51779273]; [Special Fund of State Key Laboratory of Simulation and Regulation of a Water Cycle in a River Basin, China Institute of Water Resources and Hydropower Research] grant number [SKL2018ZY05].

Acknowledgments: Thanks to the Irrigation Scheme Administration Bureau of Jiamakou Irrigation Scheme for proving relevant data. The authors wish to thank the referees for providing helpful suggestions to improve this manuscript.

Conflicts of Interest: The authors declare no conflict of interest.

\section{References}

1. Molden, D.J.; Gates, T.K. Performance measures for evaluation of irrigation-water-delivery systems. J. Irrig. Drain. Eng. 1990, 116, 804-823. [CrossRef]

2. Yakubov, M. Assessing irrigation performance from the farmers' perspective: A qualitative study. Irrig. Drain. 2012, 61, 316-329. [CrossRef]

3. Gorantiwar, S.D.; Smout, I.K. Performance assessment of irrigation water management of heterogeneous irrigation schemes: 1. A framework for evaluation. Irrig. Drain. Syst. 2005, 19, 1-36. [CrossRef]

4. Kazbekov, J.; Abdullaev, I.; Manthrithilake, H.; Qureshi, A.; Jumaboev, K. Evaluating planning and delivery performance of Water User Associations (WUAs) in Osh Province, Kyrgyzstan. Agric. Water Manag. 2009, 96, 1259-1267. [CrossRef]

5. Bautista, E.; Replogle, J.; Clemmens, A.J.; Clyma, W.; Dedrick, A.R.; Rish, S.A. Water delivery performance in the Maricopa-Stanfield Irrigation and Drainage District. Irrig. Drain. Syst. 2000, 12, 139-166. [CrossRef]

6. Shakir, A.S.; Khan, N.M.; Qureshi, M.M. Canal water management: Case study of upper Chenab canal in Pakistan. Irrig. Drain. 2010, 59, 76-91. [CrossRef]

7. Moreno-Pérez, M.F.; Roldán-Cañas, J. Assessment of irrigation water management in the Genil-Cabra (Córdoba, Spain) irrigation district using irrigation indicators. Agric. Water Manag. 2013, 120, 98-106. [CrossRef]

8. Molden, D.; Butron, M.; Bos, M.G. Performance assessment irrigation service delivery and poverty reduction: benefits of improved system management. Irrig. Drain. 2007, 56, 307-320. [CrossRef]

9. Zardari, N.; Cordery, I. Water productivity in rigid irrigation delivery system. Irrig. Sci. 2009, 23, 1025-1040. [CrossRef]

10. Hollanders, P.; Schultz, B.; Wang, S.; Cai, L. Drainage and salinity assessment in the Huinong Canal Irrigation District, NingXia, China. Irrig. Drain. 2005, 54, 155-173. [CrossRef] 
11. Xu, X.; Huang, G.H.; Qu, Z.Y.; Pereira, L.S. Using MODFLOW and GIS to assess changes in groundwater dynamics in response to water saving measure in irrigation districts of the upper Yellow River basin. Water Resour. Manag. 2011, 25, 2035-2059. [CrossRef]

12. Jiang, L.; Yang, Y.T.; Shang, S.H. Evaluation on irrigation efficiency of irrigation district in arid region based on evapotranspiration estimated from remote sensing data. Trans. Chin. Soc. Agric. Eng. 2013, 29, 95-101. (In Chinese) [CrossRef]

13. Unal, H.B.; Asik, S.; Avci, M.; Yasar, S.; Akkuzu, E. Performance of water delivery system at tertiary canal level: A case study of the Menemen Left Bank Irrigation System, Gediz Basin, Turkey. Agric. Water Manag. 2004, 65, 155-171. [CrossRef]

14. Vandersypen, K.; Bengaly, K.; Keita, A.C.T.; Sidibe, S.; Raes, D.; Jamin, J.Y. Irrigation performance at tertiary level in the rice schemes of the Office du Niger (Mali): Adequate water delivery through over-supply. Agric. Water Manag. 2006, 83, 144-152. [CrossRef]

15. Aly, A.M.; Kitamura, Y.; Shimizu, K. Assessment of irrigation practices at the tertiary canal level in an improved system-a case study of Wasat area, the Nile Delta. Paddy Water Environ. 2013, 11, 445-454. [CrossRef]

16. Meng, Q.Q. Soil Moisture Consumption Pattern and Growth Response of Apple Orchard in the Loess Plateau. Ph.D. Thesis, College of Water Resources and Architectural Engineering, Northwest Agriculture and Forestry University, Yangling, China, 2011; p. 94.

17. Liu, Y.C.; Jiang, H.A.; Li, C.D.; Huang, H.; Pan, Z.H.; Chai, C.L. Analysis of irrigation water requirement and irrigation requirement index for cotton of Hebei province. Trans. Chin. Soc. Agric. Eng. 2013, 29, 98-104. (In Chinese) [CrossRef]

18. Allen, R.G.; Pereira, L.S.; Raes, D.; Smith, M. Crop evapotranspiration: Guide-lines for computing crop water requirements. In FAO Irrigation and Drainage Paper NO. 56; FAO: Rome, Italy, 1998; 300p.

19. Guo, Y.Y. Irrigation and Drainage Engineering, 3rd ed.; China Water Power Press: Beijing, China, 1997; pp. 41-42.

20. Nam, W.H.; Hong, E.M.; Choi, J.Y. Assessment of water delivery efficiency in irrigation canals using performance indicators. Irrig. Sci. 2016, 34, 129-143. [CrossRef]

21. Sarwar, A.; Bastiaanssen, W.G.M.; Feddes, R.A. Irrigation water distribution and long-term effects on crop and environment. Agric. Water Manag. 2001, 50, 125-140. [CrossRef]

22. Ghazouani, W.; Marlet, S.; Mekki, I.; Vidal, A. Farmers' perceptions and engineering approach in the modernization of a community-managed irrigation scheme. A case study from an oasis of the Nefzawa (South of Tunisia). Irrig. Drain. 2009, 58, S285-S296. [CrossRef]

23. Vos, J. Understanding water delivery performance in a large-scale irrigation system in Peru. Irrig. Drain. 2005, 54, 67-78. [CrossRef]

(C) 2018 by the authors. Licensee MDPI, Basel, Switzerland. This article is an open access article distributed under the terms and conditions of the Creative Commons Attribution (CC BY) license (http://creativecommons.org/licenses/by/4.0/). 